\section{Exploring the Detection Limits of Chemical Microscopy}

C. Milne, C. Morris, and H.S. MacDonald Sevenoaks School, Sevenoaks, Kent,UK

Chemical microscopy techniques were once a major source of information for scientists who wanted to detect the presence of metals in samples. Many microscopists used such techniques, which, when properly applied and appropriate checks for interferences made, could conclusively prove the presence of small quantities of specific metals.

The fact that the identification could be conclusive for trace amounts following relatively simple and cheap processes, and that visual evidence resulted, made these techniques quite robust. Chamot and Mason's text "Handbook of Chemical Microscopy" is held to be a definitive resource for these techniques!. With the development of absorpion and emission based spectral analytical techniques, the application of chemical microscopy techniques dwindlad, pechaps because the skills needed by analysts using specIral techniques were to be more rapidly acquired than those inwolving miciosopy.

\section{Our present study is a result of posing two questions:}

- What are the limits of detection asscciated with microchemical techniques and can we corroborate the lower limit of detection by comparison with ICP?

- Could microchemical lechniques become a simple, useful part of the rapid screening of environmental samples for traces of heavy metal contamination?

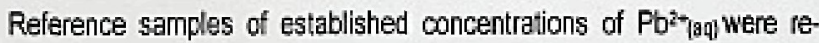
acted on microscope slides with an equal volume of $\mathrm{K}_{[\mathrm{aq}}$ of $0.01 \mathrm{M}$ concentration. The volume was reduced with gentle heating to about half that of the original. Crystallisation events were noted at the perimeter of the drops. On close examination at magnifications of $400 \mathrm{x}$ we were able to record hexagonal Pblas at concentrations as low as $1.0 \mathrm{ppm}$, but irrespective of how many times we prepared specimens. All procedures were carried out at least six times and we could not find $\mathrm{Pb}_{43}$ at any $\mathrm{Pb}^{2}{ }_{\text {ins }}$ concentrations lower than this. We prepared futher test solutions which were of $\mathrm{Pb}^{2+}{ }_{(\mathrm{iq})}$ concentrations of 990,980 and $970 \mathrm{ppb}$. The concentrations of $\mathrm{Pb}^{2} \mathrm{p}_{\mathrm{pq}}$ used in this detection technique were confirmed using inductively coupled plasma (ICP) spectros-

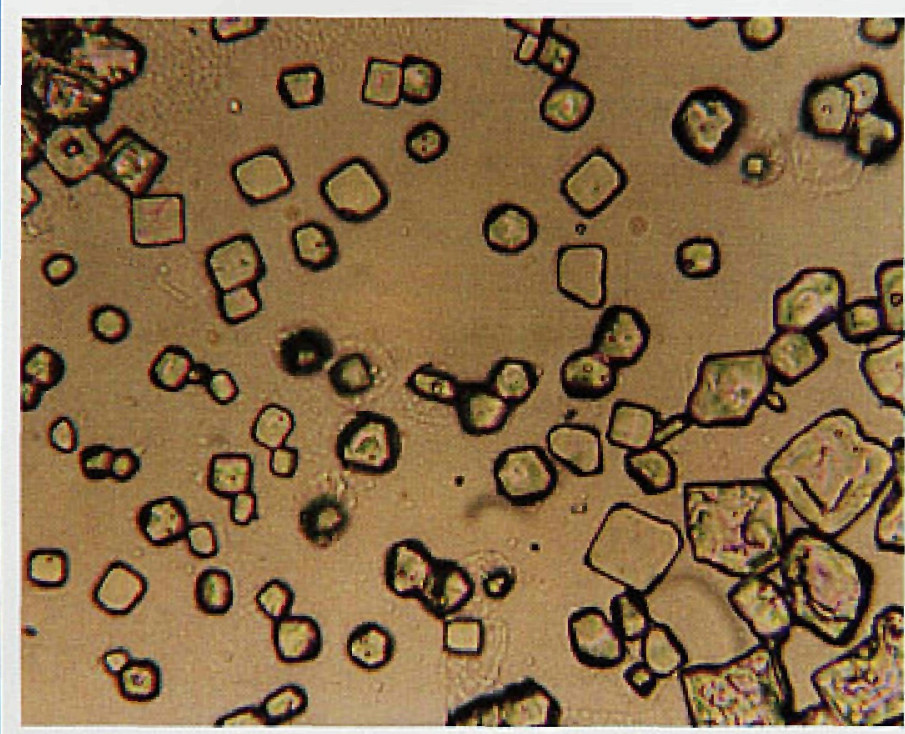

The first, a brightfield image taken using a polarising light shows several hexagonal micro-crystals of $\mathrm{Pb}_{2}$ si which were formed at $\mathrm{PB}^{2+}{ }_{\text {(aj) }}$ woncentrations as low as $1.0 \mathrm{ppm}$ (or $1 \mathrm{mg} \mathrm{L}$ ). Note that many of the hexagons are highly refractive and pleochroic. copy.

It is evident that these microchemical techniques may be used to detect $\mathrm{Fo}^{2+}{ }_{\text {|aq) }}$ at concentrations as low as $1.0 \mathrm{ppm}$, and that such measurements may be made quickly. Further work in our laboratory will explore other methods for $\mathrm{Pb}^{2+}{ }_{[a \mathrm{q}]}$ such as the triple nitrite reaction, the influence of oher ions on the minimum limit of detection, and also what the minimum limit of detection for $\mathrm{HG}_{2}{ }^{2+}$ will be. Our work to date suggests that this latter ion may be detected at concentrations as low as $600 \mathrm{ppb}$. All of our work to date suggests that these chemical microscopy techniques are simple to make, robust, and may well contribute to the rapid screening of environmental samples. They would seem to be well suited to screening processes remote from sophisticated heavy analytical equipment.

1. Chamot, E.M. and Mason, A.B. (1989) Handbook of Chemical Microscopy, vol. II, Mocrone Research Institute, Chicage, IL.

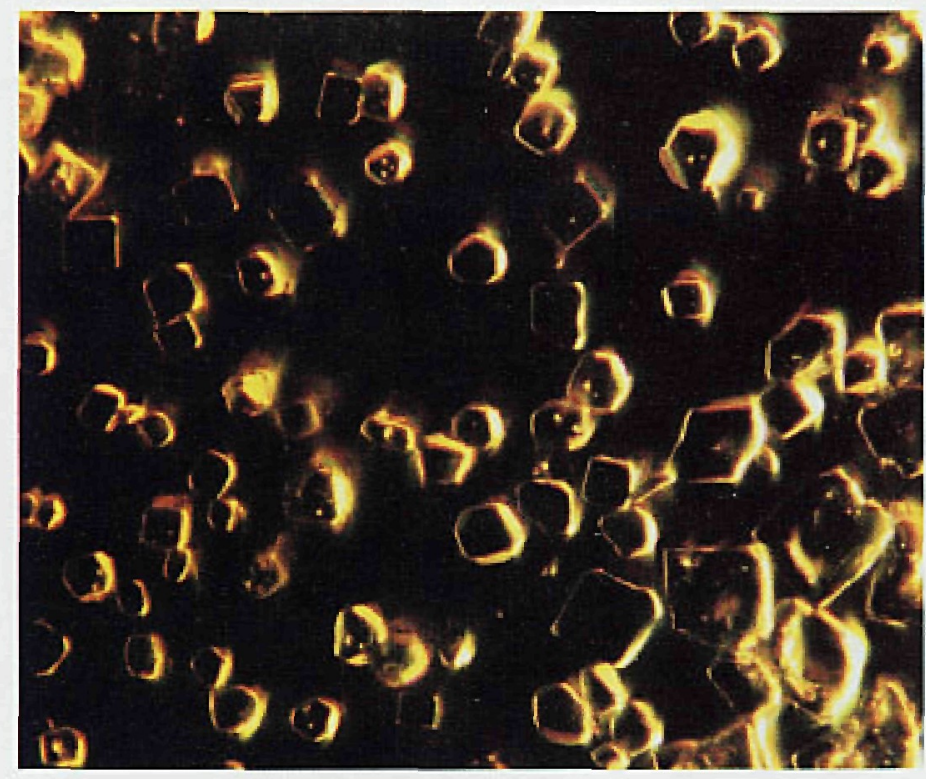

The second is a darkfield version of the same visual field. The hexagonal crystals are scattering light in such a way to suggest increased crystal growth above the plane of focus, unlike the K/4y counterparts which are commonly square in cross-sections.

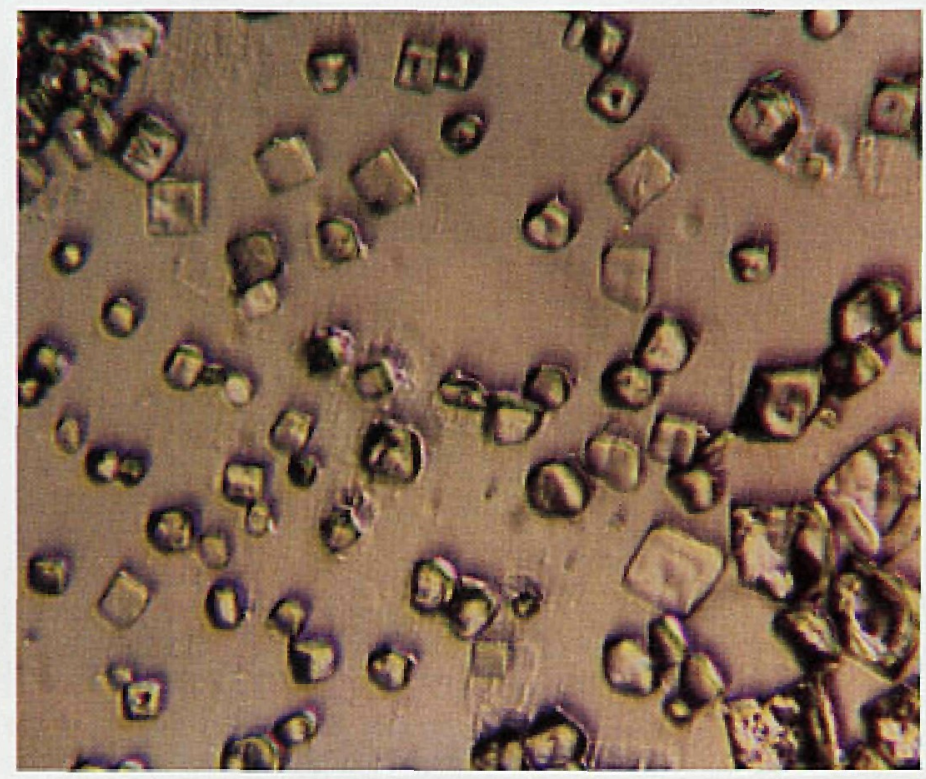

The third micrograph was taken using Hofmann Modulation Contrast (HMC) and the three dimensional difference between $\mathrm{PbL}_{2\left(\mathrm{~S}_{3}\right.}$ and $\mathrm{K}_{4 \mathrm{~S}_{3}}$ is reinforced. 

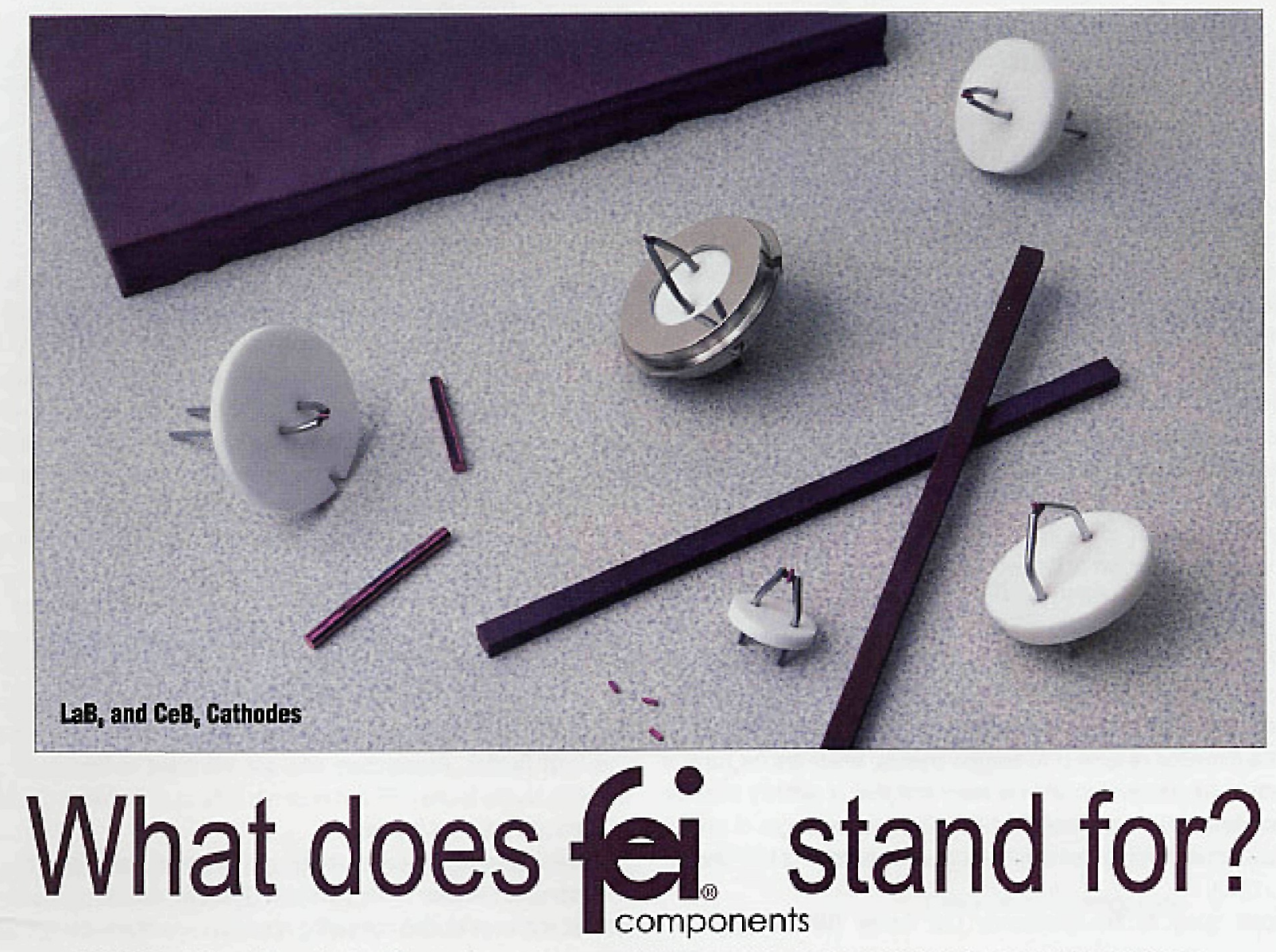

FEl's Mini Vogel Mount, the first universally compatible long-life, high-stability LaB, cathode, provides excellent performance and the best cost-per-use value for installation into your EM systems.

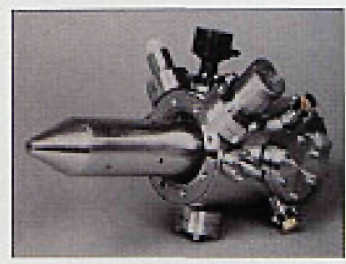

Two-Lens Focusing Column

Our compact, UHV, field emission columns are used by researchers worldwide, Innovative electrostatic optics and dedicated electronics allow you to integrate a high current density electron or ion column into most vacuum systems. FEl also supplies researchers with other specialized products.

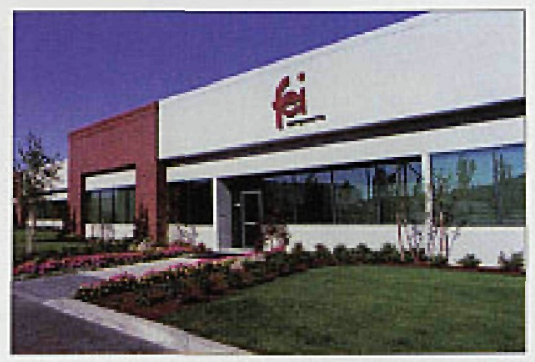

Hew Components Facilities Dedicated FEI Components Group facilities enabling new technology development through key investments in $\mathrm{F} \& \mathrm{D}$ and manufacturing.

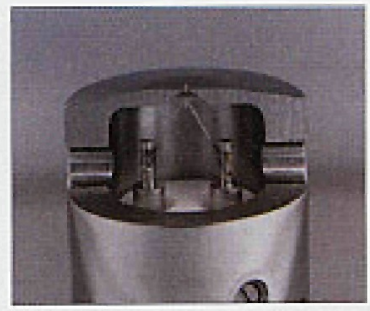

Schottky Field Emission Cathodes

FEI supplies Schottky ficld emitters to EM manufacturers worldwide. Schottky emission's high current intensity has established it as the preferred electron source for high resolution SEM,TEM, Auger, ESCA, EDX, and lithography.

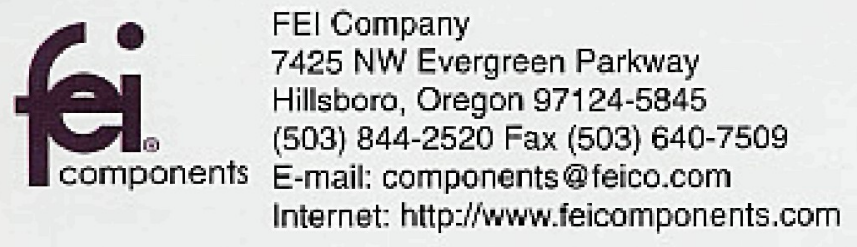

Now, when you think of FEl Components, youll' know we are the Specialists in Fiedl Electron and Ion Technology. 